\title{
Dynamics of Social Consciousness in the Methodology of Simulating Social Systems as a Way of Predicting Social Development Trends
}

\author{
Valentina Maykova \\ Mytishchi Subsidiary \\ Bauman Moscow State Technical University \\ 1st Institutskaya Str. 1 \\ Mytishchi, Moscow Region, Russian Federation 141005 \\ E-mail: valmaykova@mail.ru
}

\author{
Andrey Maykov \\ Bauman Moscow State Technical University \\ 2nd Baumanskaya Str. 5, str. 1 \\ Moscow, Russian Federation 105005 \\ E-mail: shtuder@mail.ru
}

\begin{abstract}
Presented by a technique for solving one of the problems that are instrumental for predicting development of social systems, specifically social consciousness dynamics, taking into account actual properties of the society and the interaction of all possible components of the model, which are contemporary social state structures along with non-state and external ones. The authors present a model that trajectories of social development will only evolve steadily if positive feedback is present. This generalised social model correctly describes all the transient processes accompanying transitions between states in a system, since characteristic transient state durations are sufficiently shorter than the time periods under consideration. It is determined that the foundation of contemporary social systems is an intelligent core: a package of algorithms and programs that ensure real-time optimisation of social system activity. Justified why it is necessary to use mathematical simulation to predict behaviour of social systems, which specifically involves creating a mathematical description of social system activity, notated as vectors at each moment of time representing how a social system responds to external factors.
\end{abstract}

Keywords-social systems; nonlinear processes; feedback and feed-forward; microsystems and macrosystems; microunity and macrounity; social development; stable social consciousness

\section{INTRODUCTION}

There exist several factors today that enable us to run computer simulations of dynamics and technologies that take into account the main factors affecting development of social systems: powerful computers are relatively widely available; moreover, numerous software packages and optimised integrated developer environments are suitable for simulating not only physical and chemical but also social processes. Such simulations, featuring minimum fitting coefficients and the most "universally applicable" constants, along with the ability to focus on the main parameters of a given process, make it possible to achieve adequate accuracy in estimating and predicting the ways, structure and methods of development concerning social systems, as well as conduct optimisation-related calculations [1].

\section{METHOdOLOGY OF SimUlating SOCIAL SYSTEMS: THE ESSENCE}

In order to simulate a social system, we need to define a set of input parameters and then, taking into account known social properties of a specific society and extra constraints, define a set of output functions required for estimating how the society responds dynamically to changes in input parameters.

It is possible and even necessary to account for dynamic properties of social systems (such as heterogeneity of social time, mental properties, passionarity etc.) in order to optimise modes and ensure efficiency of computation when developing mathematical models of social system components.

A characteristic feature of contemporary social systems is the existence of random disturbances, that is, the specific component makeup of values is unknown: we only have access to certain averaged properties that fluctuate over a wide range even for a specific type of values [2]. Moreover, there is a trend of varying the properties of values in time and space (for example, moral and aesthetic values will change their specifics over time). We need a distribution of the remaining constants over social structures at each point in time. These constants can include a sense of selfpreservation, tribalism, spiritual and moral values and others [3]. Then it becomes possible to derive the social system parameters describing the process at this point in time by means of solving the inverse problem, which is an optimization problem. Next we should be able to determine how to optimally affect the system so that the process would run in the optimum mode (according to a preset criterion).

Mathematically speaking, these problems fall into the domain of nonlinear programming. There are numerous techniques for solving these problems, but only a few have found any use in studying social processes as this problem is highly specific.

In essence, search techniques work the following way: for a given vector $\mathrm{x}$ a descent direction $\mathrm{d}$ is determined, then 
the function $\mathrm{f}$ is minimised along $\mathrm{d}$ using a one-dimensional optimisation technique [4].

The foundation of contemporary social systems is an intelligent core: a package of algorithms and programs that ensure real-time optimisation of social system activity. According to a number of experts, all the basic functionality of intelligent systems should be provided on the software level in two stages [5].

The first stage is developing a model of the social structure and designing algorithms and software codes for optimising system operation modes, taking into account available prior and pseudo-prior information (respectively processed stochastic data).

The second stage is developing the system algorithms per se that track deviations of external stochastic parameters from standard base modes and determine the system's optimum response, accounting for dynamic properties of components and preset constraints. Apart from those we need algorithms that provide short-term prediction of deviation from base modes.

The activity algorithm of such a social system is based on altering its elements and structure as a result of observation and processing current data so that the whole system could transition to a new optimum state over a new period of time. In order to run the system in real time, we need to develop respective models of social systems (as well as their specific elements) and specialised numerical methods.

We also have to take into account detailed models of social system components, like the models of internal processes (those of internalising values, basic communication and personal interaction, models of behaviour, social and economic ties and so on) that define the basic properties of a social system. In order to simulate the social system as a whole and solve optimisation problems, it is necessary to define a set of input parameters (mass media, enactment of legislation, influence of other states and so on) and then, taking into account known social properties of a specific society and extra constraints related to its mentality, define a set of output functions required for estimating how the system responds dynamically to changes in input parameters [6].

A social system may include a large number of social connections between various types of communities (workers, entrepreneurs, intelligentsia, oligarchic structures and others) that ensure the activity of the society.

Thus we can state the following problem for simulating social systems: determining the makeup of a social system that satisfies a person's needs in terms of social relations (communication and survival processes). The problem stated is nonlinear. In the simplest case the system may be linearised, and its solution may be the first approximation.

Using actual society characteristics is necessary for simulating social systems. A generalised social model correctly describes all the transient processes accompanying transitions between states in a system, since characteristic transient state durations are sufficiently shorter than the time periods under consideration.

So, the idea of simulating social systems means predicting social development as a response to external factors, this response being defined through conceptualising these social processes as nonlinear and considering the combination of their internal and External Dynamics Interacting With The Natural Environment.

\section{WAYS AND MEANS OF FORMING A STABLE SOCIAL CONSCIOUSNESS IN TODAY'S RUSSIA}

Plenty of works have been published by now that deal with mathematical simulation, including simulation of social processes. Recent plans of developing this methodology that were put forward by the European community looked imposing enough. The fact that we have fallen behind may be the case of the follower being in a more advantageous position than the leader. We should not adapt technological solutions known in the West but develop those the use of which in Russia may be justified in terms of politics and economics and will predict the trends of social development and prevent catastrophes. This is a highly complex task, solving which requires the effort of specialists in various fields, from those in the liberal arts (philosophers, sociologists and so on) to STEM researchers (mathematicians, software developers and others).

The trajectory of the dynamics of social consciousness is a zigzag path, which stems, for example, in Russia from switching development paradigms, in other words, from a dramatic transition from one model principle (totalitarianism) to the opposite one (democracy), from iconoclastic atheism to missionary Orthodox Christianity. At the same time, the main problems of development of social consciousness in the world of today cannot be solved without taking globalisation into account. This is why formation and dynamics of social consciousness taken as a method of predicting social development trends is not a simple task [7]. Structural and systems analysis of the problem at hand looks to be the most promising. It involves isolating and formalising the main parameters affecting the final solution. [8] This approach worked quite well for investigating mass communication. Political scientists consider two models of mass communication: the mathematical one (by C. Shannon) and the cybernetic one (by N. Wiener) [9]. The works of C. Shannon dealt with problems of information transfer in complex systems. M.N. Grachev proposes a methodology and a model for studying political processes [10]. The works of A.P. Mikhaylov show that even a relatively low number of assumptions makes it possible to construct quite meaningful mathematical models that are also easy to study. These models deal with a system consisting of state power and civil society, and simulation results can be clearly interpreted in respective terms.

This work presents an approach featuring elements of analysis and simulation that enables us to perform qualitative analysis of the prospects of developing a stable social consciousness. We should emphasise that we are not talking about quantitative indices per se, but about comparative 
analysis of the processes concerning formation and dynamics of social consciousness. As the main parameters we select the following social structures shaping the social consciousness: state, non-state and external structures.

Each group forms its own social consciousness featuring its own structure and determines the direction of development (a vector or a trend) for both the society and social consciousness via respective social institutions and means of communication. The total development vector and social consciousness structure are the sum of individual vectors and structures. This way, according to control theory (for example, Shannon, Wiener), each group is a control system (centre), and a development vector is a controlled parameter. In order to describe dynamics of social consciousness we introduced feedback into the model. According to the general definition of feedback, it involves a connection between the control system (the groups in the model) and controlled parameters (the development vector and its structure) [11]. Positive feedback increases the effect of a given group, while negative feedback decreases it. Strong negative feedback leads to significant instabilities resulting in drastic changes in the vector of the dynamics of social consciousness and a change in the form of the state power towards either dictatorship or anarchy [12].

\section{MODEL OF THE DYNAMICS OF SOCIAL CONSCIOUSNESS}

"Fig. 1" schematically represents our model. Let us formalise the problem: in the general case the following social structures forming the social consciousness should be the main parameters: state, non-state and external structures (figure 1). Group1 includes the authorities. Individual citizens, families, and various associations (professional, religious, cultural etc.) are all non-state structures. They are marked in the figure 1 as Group2, ..., Groupn-1. External structures (Groupn) comprise other states (their authorities, various social groups etc).

Each structure forms social consciousness via respective social institutions and means of communication, such as government institutions, education, mass media and so on. This social consciousness is characterised by a vector (V1, $\mathrm{V} 2, \ldots, \mathrm{Vn}-1, \mathrm{Vn})$ and a value (SC1, SC2, .., SCn-1, SCn). The total social consciousness $\mathrm{SC}$ is the sum of the $\mathrm{SC}$ values

$$
\mathrm{SC}=\mathrm{SC} 1+\mathrm{SC} 2+\ldots+\mathrm{SCn}-1+\mathrm{SCn}
$$

The total social consciousness vector $\mathrm{V}$ (the direction) is a sum of all vectors

$$
\mathrm{V}=\mathrm{V} 1+\mathrm{V} 2+\ldots+\mathrm{Vn}-1+\mathrm{Vn}
$$

The social consciousness SC along with the vector V affects social structures via feedback (see figure 1), which, in turn, form vectors $\mathrm{V} 1, \mathrm{~V} 2, \ldots, \mathrm{Vn}-1, \mathrm{Vn}$ and values $\mathrm{SC} 1$, $\mathrm{SC} 2, \ldots, \mathrm{SCn}-1, \mathrm{SCn}$ via respective social institutions and mass media, and accordingly $\mathrm{V}$ and $\mathrm{SC}$ as per equations (1) and (2). We should note that the feedback (dash lines in "Fig. 1 ) may be both positive and negative. The vector $\mathrm{V}$ shapes the direction of the social development trajectories at various points in time.

Let us qualitatively consider development dynamics as a function of system parameters:

1) let Group1 (authorities) dominate the system. It means that only the first terms of the equations (1) and (2) determine both the vector $\mathrm{V}$ and the value SC. All other terms are negligibly small. Dictatorship becomes a possible direction in which the system develops.

2) the effect of Groupn (external structures) is strong. The trajectory is only determined through external factors, which leads to a loss of sovereignty.

3) the effect of Group2,..., Groupn-1 or several of these is noticeably larger than that of the others; moreover, vectors $\mathrm{V} 2, \ldots, \mathrm{Vn}-1$ point in opposite directions. In this case, anarchy is possible.

Let us qualitatively consider the issues of stable system development. The truth today is that the society is fractured and communication between various groups becomes problematic. It means that vectors $\mathrm{V} 1, \mathrm{~V} 2, \ldots, \mathrm{Vn}-1, \mathrm{Vn}$ may frequently point in opposite directions. How is the system going to develop in this case? Let the vector $\mathrm{Vk}$ of the Groupk be markedly different from the total vector $\mathrm{V}$ but lie within the field on the right. Then due to negative feedback the protest effect of the Groupk will increase, which may lead to a change in the total vector $\mathrm{V}$. An attempt to return to the previous vector $\mathrm{V}$ (for example, initiated by the authorities) will improve the situation at a certain point in time, but then protests will increase again, and so on. The magnitude of oscillations will increase (trajectories 1 and 3 in figure 1), hence both dictatorship and anarchy may be possible. The situation becomes significantly more complex when antagonism between various groups is present. While analysing development of social consciousness, one should note that vectors $\mathrm{V} 1, \mathrm{~V} 2, \ldots, \mathrm{Vn}-1, \mathrm{Vn}$ are heterogeneous time-wise, that is, characteristic times over which changes in the vectors happen are noticeably different. The vector V1, which corresponds to the state, is the most conservative (for example, legislative procedures, elections and other processes require considerable timescales). If there appears any disagreement between the state V1 and individual groups V2, ..., Vn-1, due to feedback (figure 1), consolidation of the whole protest movement may happen due to its mobility (timescales involved are short). A negative resonance like that may lead to significant instability. 


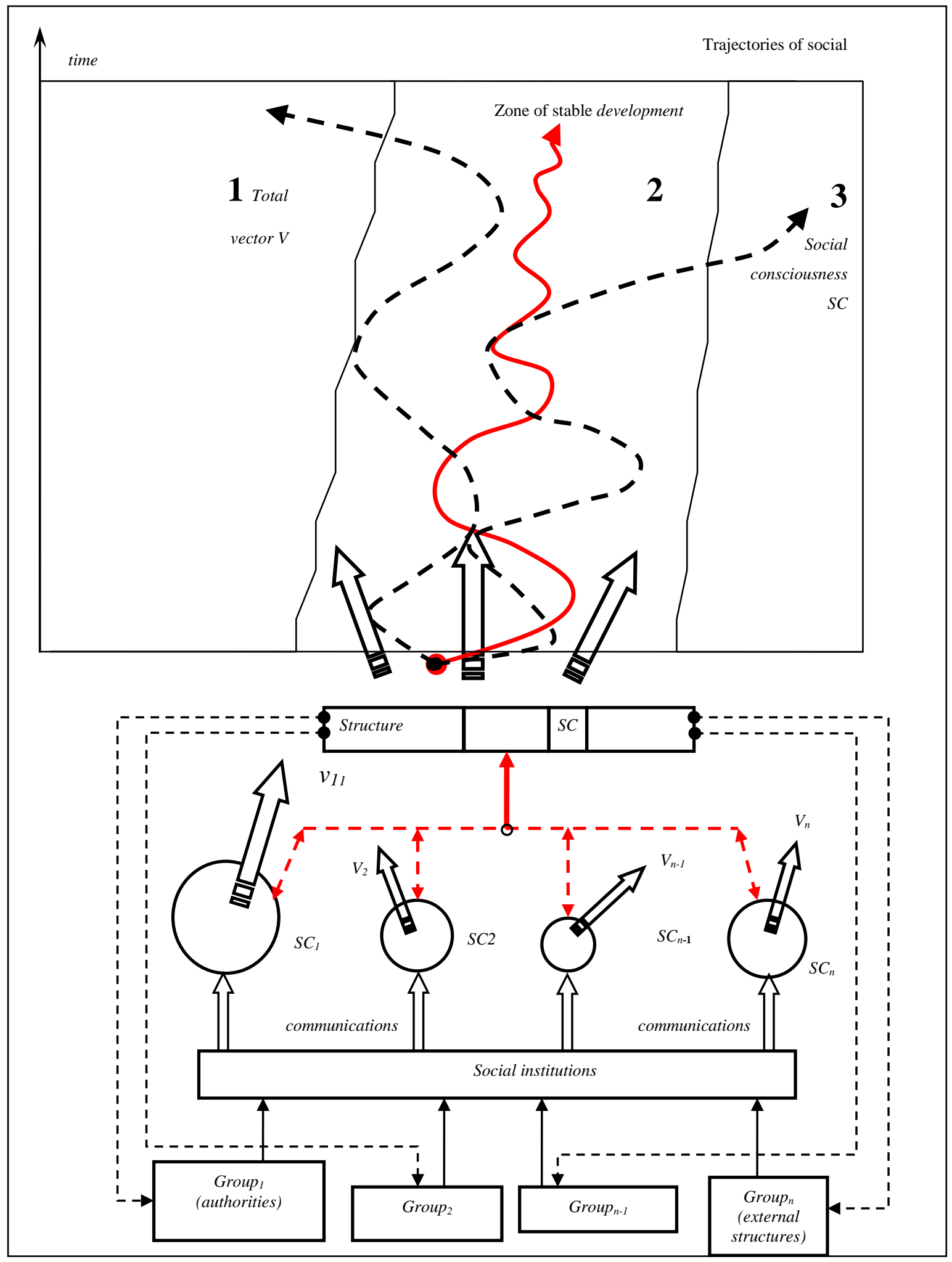

Fig. 1. Model of the dynamics of social consciousness.

Therefore, the only stable development path involves introducing positive feedback into the system. What is the meaning behind this feedback? For all the difference in terms of directions characterising the vectors of social consciousness of various groups, it is necessary to determine which components of the social consciousness share the same direction. The next step is adjusting the direction of the vectors of social consciousness so that their common 
components increase (or do not decrease at the very least). This way, the component common to all the vectors $\mathrm{V} 1, \mathrm{~V} 2, \ldots, \mathrm{Vn}-1, \mathrm{Vn}$ will also increase in the total vector $\mathrm{V}$. The magnitude of development trajectory oscillations will decrease over time, or at least it will not increase (trajectory 2 in "Fig. 1").

Let us consider the dynamics of social consciousness in today's Russia using the model we developed. During the Soviet times, the authorities determined social consciousness. Effects of all the other groups were negligibly small, but due to negative feedback, protest movement grew (the vectors of social consciousness formed by the state and the society were opposite), which led to the dissolution of the USSR (a negative resonance). Further decrease of the role played by the authorities resulted in numerous different groups appearing in Russia. A parade of sovereignties, oligarchic structures, and criminal organisations arose, becoming a competition to the authorities and forming a particular type of social consciousness. The consciousness of the society was fractured (numerous V2,..,Vn-1,Vn, with opposite directions). The state entered a period of unstable development, which may have led to dissolution of Russia, a civil war, and anarchy. In order to maintain the unity of the country, steps were taken to strengthen the state power, select development priorities, decrease the effect of other states and form a respective social consciousness based on the principles of sovereignty, independence and selfsufficiency of the Russian state (V.V. Putin, April 24th, 2013). Today's Russia is an arena of numerous groups of people opposing each other, each professing their own values: liberals and supporters of the state, super-rich elites and impoverished masses, "our kind" and "not our kind", immigrants and locals, Russians and non-Russians, the religious and the atheists, football fans and others, the conflicts among which will often turn physical. [13] External influences are increasing through introduction of Western neo-liberal values, which have led to an unexpected opposite result when the Muslim Brotherhood, promoting traditional Muslim values, came to power in countries such as Egypt or
Morocco. This resulted in war. Russian society is now living in a period of dangerous instability [14].

Let us elaborate on the concept of positive feedback in the framework of our model. Firstly, we should determine the trend of the social development (and accordingly, the vector $\mathrm{V}$ ). This trend should be capable of consolidating the society; every social group should have things in common with other groups, despite all the contradictions, so that civil society could be built. The first step towards consolidation is selecting (or formulating) the national idea based on the analysis of the state the society is in (politics, economics and so on). Potential correction of this idea based on dialogue [15] (finding a vector common to all the social groups) is a prerequisite to consolidation.

\section{MiCRO- AND MACROSYSTEMS AS STABILITY LEVELS IN SOCIAL SYSTEMS}

Our model enables us to consider dynamics of stable development of social systems represented as a chain satisfying the conditions $\mathrm{V} 0>>\mathrm{V} 1>>\ldots \mathrm{VN}-1>>\mathrm{VN}$, that is, the macrosystem of social structures may be represented as a system consisting of smaller systems (microsystems), each of which in turn consists of even smaller ones and so on. Each system of microsystems (in terms of the order of smallness) may be formally characterised by the level i, which is defined by the scale of the effective microsystem radius ri (ri+1 $<<$ ri $<<$ ri- 1$)$. The number of levels is finite $(\mathrm{i}=1 \ldots \mathrm{N})$. In a system like that, microsystems of each level (apart from the level $\mathrm{N}$ ) are characterised by their qualitative and quantitative properties. Our model of the dynamics of social consciousness shows that social systems as macrosystems and microsystems may be considered only in terms of integrity of each system. Holistic social systems exist in the broad and narrow senses. In the narrow sense, microunity is a spiritual form of the holistic social being, the ultimate unit of which is an individual.

In the broad sense, macrounity is the realisation of human activity on the planetary scale, when a human being can both understand social being and affect it globally.

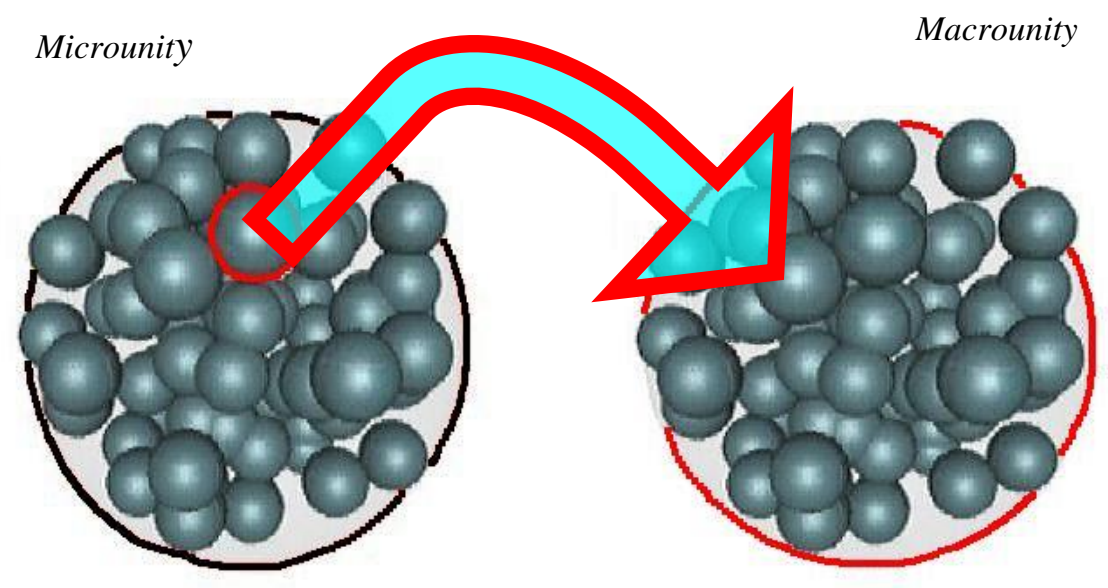

Fig. 2. Microunity Macrounity. 
In this case holistic social consciousness requires considering objects not only in terms of a state, but also as regards their global importance. The ultimate unit of macrounity is the humankind of the planet Earth. Social communities, states, associations (professional, religions and others) may be considered both in terms of microunity and macrounity.

The mathematical description simulating the social system activity is notated as a vector direction at each moment of time representing how a social system responds to external factors (exiting the optimum mode at a certain period of time) [16]. The algorithm describing operation of such a social system is based on altering its parameters and structure as a result of observation and processing current data so that the whole system could transition to a new optimum state over a new period of time [17]. In order to run the system in real time, we need to develop respective models of social systems (as well as their specific elements) and specialised numerical methods.

\section{CONCLUSION}

Mathematically simulating social systems means conceptualising these social processes as nonlinear and considering the combination of their internal and external dynamics interacting with the natural environment changing as a result of social activity. The algorithm describing operation of such a social system is based on altering its parameters and structure as a result of observation and processing current data so that the whole system could transition to a new optimum state over a new period of time.

\section{REFERENCES}

[1] Mikhaylov A.P. Simulating the evolution of power distribution in state hierarchies // Herald of the Russian Social Political Centre Fund. 1996. No. 2. Pp. 26-39.

[2] Nekhamkin V.A. A Counterfactual Challenge of the Past: Ways of Negotiation // Herald of the Russian Academy of Sciences. 2017. Vol. 87. No. 2. Pp. 191-198. DOI: 10.1134/S1019331617020046.

[3] Ivlev V.Yu., Oseledchik M.B. Methodological principles for the introduction of modality categories in modern scientific cognition // Proceedings of the 3-rd International Conference on Arts, Design, and Contemporary Education. (ICADCE 2017) Advances in Social Science, Education and Humanities Research. Paris: Atlantis Press, 2017. V.144. Pp.541-545.

[4] Maykov I.L., Direktor L.B. Solving the problems of optimisation and control for hybrid power systems in the structure of distributed generation. Large-Scale Systems Control. No. 35. Moscow, Trapeznikov Institute of Control Sciences of Russian Academy of Sciences, 2011. Pp. 250-264.

[5] Mikhailov A.P. Efficient Strategies of Corruption Suppression in State Power Hierarchies // Proceedings of 15th IMACS World Congress, 2007. Berlin. V. III. Pp. 727-732.

[6] Gubanov N.I., Gubanov N.N. The role of mentality in the development of society: sociocultural hypothesis // Vestnik slavianskikh kultur-bulletin of slavic cultures-scientific and informational journal. 2017. Vol. 43. № 1. P. 38-51.

[7] Maykova V.P. Structure and dynamics of social consciousness // Bulletin of Moscow Region State University / Available at: www.evestnik-mgou.ru. 2014. No. 1. Pp. 1-8.

[8] Shannon C. Works on the information theory and cybernetics. Moscow, Foreign Literature Publ. 1963 (in Russian).
[9] Wiener N. Cybernetics: Or Control and Communication in the Animal and the Machine. 2nd revised ed. MIT Press, 1961. [In Russ.: Wiener N. Control and Communication in the Animal and the Machine. New Chapters of Cybernetics. Moscow, Sovetstkoe Radio. 1968.]

[10] Grachev M.N. Political communication // RUDN Journal of Political Science, 1999. No. 1.

[11] Maykova V.P. Holistic approach to cognition theory problems. Ideas. Methods. Solutions. LAP LAMBERT Academic Publishing. Berlin. 2011. 70 p. ISBN: 978-3-8454-1298-6

[12] Aron R. Dimensions de la conscience historique [Dimensions of the historical consciousness]. Paris, Plon. 1961. [In Russ.: Aron R. Dimensions of the historical consciousness. Moscow. 2010.]

[13] Suzdaleva T.R. Migratory processes in the context of geopolitics // Vestnik Tomskogo gosudarstvennogo universiteta-Filosofiyasotsiologiya-politologiya-Tomsk state university journal of philosophy sociology and political science. 2016. № 3 (36). P. 237 244. DOI: $10.17223 / 1998863 X / 35 / 25$.

[14] Gubanov N.I., Gubanov N.N. Global mentality as a pre-condition of civilizations' conflict prevention // Sotsiologicheskie issledovaniya. 2011. № 4. P. 51-58.

[15] Chumakov A.M., Korolev A.D., Dakhin A.V. Philosophy in the world of today: a dialogue of worldviews // Problems of Philosophy. 2013. No.1. Pp. 3-16.

[16] Oseledchik M.B., Ivlev V.Yu., Ivleva M.L. Using social networks in knowledge management system // Proceedings of the 2nd International Conference on Culture, Education and Economic Development of Modern Society (ICCESE 2018). Moscow, Russia. Pp. 911-914.

[17] Oseledchik M.B., Ivlev V.Yu., Ivleva M.L. A new paradigm for analysing knowledge transfer processes // Proceedings of 4th International Conference on Education, Language, Art and Intercultural Communication (ICELAIC 2017) Part of the series ASSEHR. Moscow, Russia. Pp. 766-770. 